\title{
Pendidikan Kesehatan Tentang Jajanan dan Makanan Sehat Pada Masa Pandemi Covid-19 Di TPQ Warisatul Muslimin Tuntang
}

\author{
Winarsih ${ }^{1}$, Wiwin Hidriyawati \\ Prodi DIII Kebidanan Sekolah Tinggi Ilmu Kesehatan AKBIDYO \\ e-mail:1winarsihakbidyo@gmail.com, ${ }^{2}$ winwin.f815@gmail.com
}

\begin{abstract}
ABSTRAK Kesehatan merupakan salah satu aspek dari kehidupan masyarakat mutu hidup, produktifitas tenaga kerja, angka kesakitan dan kematian yang tinggi pada bayi dan anak-anak, menurunnya daya kerja fisik serta terganggunya perkembangan mental adalah akibat langsung atau tidak langsung dari masalah gizi kurang di Indonesia., metode, hasil, dan kesimpulan. Anak merupakan suatu kelompok generasi penerus bangsa yang mempunyai potensi dalam memajukan pembangunan di masa yang akan datang, pembentukan sumber daya manusia (SDM) di mulai sejak pada masa sekolah merupakan generasi penerus bangsa salah satu hal penting yang menjadi perhatian serius saat ini adalah jajan anak 2 sekolah, menunjukkan terdapat 1500 juta kejadian penyakit bawaan makanan dengan jumlah penderita meninggal sebanyak 3 juta [1]. Menurut FAO Makanan jajanan berkontribusi terhadap asupan energi dan zat gizi seseorang, dengan kisaran 10\%-25\% dari total konsumsi setiap hari [2].Makanan ringan ini sering kita jumpai di toko-toko, ataupun di supermarket terdekat. Metode yang digunakan adalah ceramah dan Tanya jawab tatap muka door to door ke rumah masing - masing peserta melalui kegiatan penyuluhan. Sasaran adalah anak SD didesa Cikal Tuntang Kabupaten Semarang di RT 2 RW 3 dengan jumlah 10 anak. Evalusi dengan mengerjakan soal pre sebelum di lakukakan ceramah dan post setelah ceramah dengan jumlah soal 10 dalam bentuk multiple choice. Pengabdian dengan model penyuluhan tentang Jajanan dan Makanan Sehat pada masa pendemi, mendapat sambutan yang antusias dari peserta hal ini terlihat dari diskusi yang terjadi setelah ceramah selesai disampaikan. Proses penyuluhan berjalan dengan lancar dan semua peserta dan penyuluh mengikuti protkol COVID - 19. Hasil pengolahan data didapat bahwa terjadi peningkatan pengetahuan $41,67 \%$ dari semua peserta setelah di lakukan post-test. Saran yang diberikan perlu terus diadakan penyuluhan dengan tema pendidikan kesehatan lain yang tepat untuk anak SD.
\end{abstract}

Kata Kunci : Pendidikan Kesehatan; Jajanan dan Makanan Sehat; Pandemi Covid19

- ABSTRACT Background: Health is one aspect of people's lives, quality of life, labor productivity, high morbidity and mortality rates in infants and children, decreased physical work power and impaired mental development are a direct or indirect result of malnutrition. in Indonesian., methods, results, and conclusions. Children are a group of the nation's next generation that has the potential to advance development in the future, the formation of human resources $(H R)$ starting from the school period is the nation's next generation. schools, shows that there are 1500 million cases of foodborne illness with 3 million deaths (WHO, 2013). According to FAO Snack foods contribute to a person's energy and nutrient intake,

$\overline{\text { Winarsih............. Pendidikan Kesehatan Tentang Jajanan dan Makanan Sehat }}$ 
with a range of 10\%-25\% of total daily consumption (Safriana, 2012). We often find these snacks in shops, or in the nearest supermarket.

Methods: The method used is lectures and face-to-face question and answer door to door to each participant's house through outreach activities. The target is elementary school children in Cikal Tuntang village, Semarang Regency in RT 2 $R W 3$ with a total of 10 children. Evaluation by doing pre questions before the lecture and post after the lecture with a total of 10 questions in the form of multiple choice.

Results $\therefore$ The service with the counseling model on Snacks and Healthy Food during the pandemic, received an enthusiastic response from the participants, this could be seen from the discussion that took place after the lecture was delivered. The counseling process went smoothly and all participants and extension workers followed the COVID-19 protocol. The results of data processing showed that there was an increase in knowledge of $41.67 \%$ of all participants after the post-test was carried out. The advice given needs to continue to be held counseling with other appropriate health education themes for elementary school children.

Keywords: Health Education; Snacks and Healthy Food; Covid-19 pandemic

\section{Pendahuluan}

Kesehatan adalah keadaan sehat,baik secara fisik,mental, spiritual maupun sosial yang memungkinkan setiap orang untuk hidup produktif secara sosial dan ekonomis. Hal ini disebabkan untuk mengantasipasi serta mewujudkan perlindungan masyarakat pekerjaan Indonesia dimasa yang akan datang, yang akan hidup dalam lingkungan dan perilaku sehat, memperoleh pelayanan kesehatan yang bermutu secara adil dan merata,serta memiliki derajat kesehatan yang setinggi-tinggnya. Untuk itu perlu dilakukan upaya untuk mewujudkan derajat kesehatan yang optimal bagi masyarakat dengan pendekatan penngkatan kesehatan (promotif), pencegahan penyakit (prenventif), penyembuhan penyakit (kuratif), pemulihan kesehatan (rehabilitatif), yang dilakukan secara menyeluruh, terpadu dan berkesinambungan, sesuai dengan UU kesehatan No. 36 tahun 2009 [3]

Kesehatan merupakan salah satu aspek dari kehidupan masyarakat mutu hidup, produktifitas tenaga kerja, angka kesakitan dan kematian yang tinggi pada bayi dan anak-anak, menurunnya daya kerja fisik serta terganggunya perkembangan mental adalah akibat langsung atau tidak langsung dari masalah gizi kurang. Makanan yang sehat merupakan bagian yang esensial bagi proses pertumbuhan dan perkembangan anak, serta sebagai dasar pemeliharaan kesehatan, baik bagi anak maupun orang dewasa. Sejalan dengan perkembangan zaman, semakin banyak bahan kimia yang dikembangkan dan digunakan sebagai bahan tambahan dalam jajanan dan makanan. Tujuan penggunaan zat-zat tersebut antara lain sebagai taste enhancer, food coloring, dan preservatives. [4]

Makanan jajanan adalah makanan dan minuman yang dipersiapkan dan dijual oleh pedagang kaki lima yang langsung dimakan atau dikonsumsi tanpa pengolahan atau persiapan lebih lanjut. Anak merupakan suatu kelompok generasi penerus bangsa yang mempunyai potensi dalam memajukan pembangunan di masa yang akan datang, pembentukan sumber daya manusia (SDM) di mulai sejak pada masa sekolah merupakan generasi penerus bangsa salah satu hal penting yang menjadi perhatian serius saat ini adalah jajan anak 2 sekolah, menunjukkan terdapat 1500 juta kejadian penyakit bawaan makanan dengan jumlah penderita meninggal sebanyak 3 juta [1]. 
Menurut FAO jajanan didefenisikan sebagai makanan dan minuman yang dipersiapkan dan dijual oleh pedagang kaki lima di jalanan dan tempattempat umum lainnya yang langsung dikonsumsi tanpa pengolahan atau dipersiapkan lebih lanjut [5]. Makanan jajanan juga dapat menjadi penumbang zat gizi dari makanan yang dikonsumsi seseorang. Makanan jajanan berkontribusi terhadap asupan energi dan zat gizi seseorang, dengan kisaran 10\%-25\% dari total konsumsi setiap hari [2]. Makanan ringan ini sering kita jumpai di toko-toko, ataupun di supermarket terdekat. Jajanan yang dijual pedagang keliling sering berada di depan lingkungan sekolah.. Badan Pengawasan Makanan dan Minuman menyatakan terdapat 40\% jajanan tidak layak dimakan. Kandungan boraks, serta formalin masih mendominasi kandungan zat-zat berbahaya pada jajanan anak-anak di sekolah-sekolah. Jajanan di sekolah memang beranekaragam dan lebih menarik minat daripada bekal yang dibawa dari rumah. Namun jajanan yang menarik tersebut justru miskin gizi dan jauh dari kata sehat[2].

Berkaitan dengan fenomena diatas, maka perlu adanya pendidikan kesehatan melalui penyuluhan mengenai macam-macam, pengolahan, dan kelayakan konsumsi jajanan yang banyak dijual agar anak-anak dapat mengerti sehingga dapat memilih dan membedakan antar jajanan yang sehat dan tidak. Sehingga pada kesempatan kali ini akan membahas tentang seperti apakah jajanan yang sehat yang bergizi guna pertumbuhan dan perkembangan seorang anak.

\section{Metode}

Metode yang digunakan dalam kegiatan ini adalah melalui penyuluhan dengan ceramah. Dalam proses penyuluhan menggunakan media PPT. Penyuluhan dilakukan dengan proses door to door mengunjungi sasaran dengan jumlah 10 anak SD dimana anak SD tersebut yang berdomisili di wilayah RT 2 RW 3 Desa Cikal Tuntang. Kemudian dibuka juga sesi diskusi dan tanya jawab. Sebelum dimulai peserta diberikan lembar pretest kemudian selesai penyuluhan diberikan lembar posttest sebagai bahan evaluasi kegiatan penyuluhan.

\section{Hasil dan Pembahasan}

Pelaksanaan kegiatan pengabdian kepada masyarakat dengan metode penyuluhan tentang Pendidikan Kesehatan Jajanan dan Makanan Sehat di Era Pandemi COVID-19 dengan jumlah peserta 10 anak, dimana anak tersebut masih sekolah SD yang tergabung didalam TPQ Warisatul Muslimin. Pelaksanaan penyuluhan dilaksanakan pada hari Rabu, tanggal 30 Juni 2021. Peserta hanya berjumlah 10 dikarenkan saat ini di lingkungan kami sedang melonjak kejadian Corona sehingga demi menerapkan Prokes selama pandemi sehingga terjadi pembatasan. Alasan kenapa tidak menggunakan media online karena banyak dari keluarga yang masih mengalami kesulitan menggunakan media online.

Pengabdian yang dilakukan di TPQ Warisatul Muslimin dimulai dengan persamaan persepsi dengan peserta kemudian pemberian soal pre-test, kemudian ketua pengabdian memberikan materi secara singkat menggunakan media PPT. Saat sesi dikusi banyak sekali peserta yang bertanya seputar materi yang diberikan, sehingga penyuluhan berjalan dengan lancar. Setelah selesai memberikan materi dan sesi dikusi tim pengabdian mmeberikan soal posttest untuk melihat bagaimana peningkatan pengetahuan setelah diberikan penyuluhan. Saat proses mengerjakan soal pre maupun post peserta dilarang menggunakan HP untuk mencari jawaban di Google. Soal yang diberikan baik 
pre maupun post berjumlah 10 soal berupa Multhipel Choice dengan kunci jawaban sebagai berikut :

Tabel 1.1 Soal Pretest dan Posttest 10 soal Multiple Choice

\begin{tabular}{|c|c|}
\hline Uraian pertanyaan & Jawaban \\
\hline $\begin{array}{l}\text { 1. Apakah yang dimaksud dengan Jajanan Sehat? } \\
\text { A. Jajanan yang mahal } \\
\text { B. Jajanan yang murah } \\
\text { C. Jajanan yang enak } \\
\text { D. Jajanan yang bebas dari debu, Pewarna buatan dan } \\
\text { penyedap rasa yang berlebihan }\end{array}$ & $\mathrm{D}$ \\
\hline $\begin{array}{l}\text { 2. Makanan dikatakan bebas dari cemaran kimia apabila ? } \\
\text { A. Makanan bebas dari debu, rambut, pasir, dan kerikil } \\
\text { B. Makanan yang bebas dari kuman } \\
\text { C. Makanan yang bebas dari formalin dan boraks } \\
\text { D. Makanan yang bebas dari lalat dan kecoa }\end{array}$ & $\mathrm{C}$ \\
\hline $\begin{array}{l}\text { 3. Ciri - ciri kerupuk upil yang mengandung pewarna buatan } \\
\text { adalah ? } \\
\text { A. Warna tidak terlalu mencolok } \\
\text { B. Warna sangat mencolok } \\
\text { C. Rasa enak } \\
\text { D. Tekstur renyah dan garing }\end{array}$ & $\mathrm{B}$ \\
\hline $\begin{array}{l}\text { 4. Apakah yang dilakukan sebelum mengkonsumsi makanan } \\
\text { A. Membagikan kepala teman } \\
\text { B. Mencuci tangan dengan sabun } \\
\text { C. Mencuci rambut } \\
\text { D. Jawaban a, b, dan c benar }\end{array}$ & $\mathrm{B}$ \\
\hline $\begin{array}{l}\text { 5. Bagaimana ciri - ciri dari pentol yang mengandung borak ? } \\
\text { A. Pentol berwarna mencolok } \\
\text { B. Tekstur sangat kenyal dan berwarna agak putih } \\
\text { C. Berwarna abu atau kecoklatan } \\
\text { D. Jawaban a, b, dan c benar }\end{array}$ & $\mathrm{D}$ \\
\hline $\begin{array}{l}\text { 6. Contoh makanan yang mengandung pewarna buatan yang } \\
\text { berlebihan adalah? } \\
\text { A. Saos bakso } \\
\text { B. Roti pandan } \\
\text { C. Pudding Strawberry } \\
\text { D. Coklat }\end{array}$ & $\mathrm{A}$ \\
\hline $\begin{array}{l}\text { 7. Penyakit yang ditimbulkan jika mengkonsumsi makanan yang } \\
\text { tidak ditutup dan dihinggapi lalat? } \\
\text { A. Diare } \\
\text { B. Sakit Gigi } \\
\text { C. Pilek } \\
\text { D. Batuk }\end{array}$ & $\mathrm{A}$ \\
\hline $\begin{array}{l}\text { 8. Bagaimana cara memilih makanan yang sehat dan aman ? } \\
\text { A. Pilihlah makanan dan minuman yang tidak kadaluarsa } \\
\text { B. Pilihlah makanan dan minuman yang tidak berwarna } \\
\text { mencolok } \\
\text { C. Hindari Makanan jajanan yang digoreng dengan minyak } \\
\text { D. Pang berulang } \\
\text { Pilihan a,b dan c benar }\end{array}$ & $\mathrm{D}$ \\
\hline
\end{tabular}


9. Berikut merupakan jenis jajanan yang tidak sehat, Kecuali .. $\mathrm{D}$

A. Nugget dengan saos yang berwarna hitam

B. Es sirup warna warni

C. Gorengan dengan minyak yang sudah berwarna hitam

D. Biskuit

10. Berikut merupakan hal - hal yang harus diperhatikan sebelum membeli makanan jajanan Kecuali

A. Kemasan atau pembungkus yang digunakan

B. Kebersihan lingkungan sekitar tempat berjualan

C. Alat yang digunakan untuk mengolah dan mneyajikan

D. Jenis baju yang digunkaan pedagang saat berjualan

Hasil evaluasi yang didapatkan melalui pemberian pretest dan posttest dengan soal yang sama adalah sebagai berikut :

Tabel 1.2 Hasil Pre-Post Test 10 soal Multiple Choice

\begin{tabular}{|c|c|c|c|c|}
\hline $\begin{array}{l}\text { Nama Anak } \\
\text { ( panggilan) }\end{array}$ & Item Soal & $\begin{array}{l}\text { Hasil } \\
\text { Pretest }\end{array}$ & $\begin{array}{l}\text { Hasil } \\
\text { Posttest }\end{array}$ & Mean \\
\hline An. Hasna & Pengertian Jajanan Sehat & 9 & 10 & 1 \\
\hline An. Rafii & $\begin{array}{l}\text { Makanan dikatakan bebas dari } \\
\text { cemaran kimia apabila? }\end{array}$ & 5 & 8 & 3 \\
\hline An. Dwi & $\begin{array}{l}\text { Ciri - ciri kerupuk upil yang } \\
\text { mengandung pewarna buatan adalah } \\
? \\
\text { Warna }\end{array}$ & 7 & 9 & 2 \\
\hline An. Janur & $\begin{array}{l}\text { Apakah yang dilakukan sebelum } \\
\text { mengkonsumsi makanan? }\end{array}$ & 5 & 7 & 2 \\
\hline An. Fharil & $\begin{array}{l}\text { Bagaimana ciri - ciri dari pentol } \\
\text { yang mengandung borak? }\end{array}$ & 5 & 8 & 3 \\
\hline An. Nisa & $\begin{array}{l}\text { Contoh makanan yang mengandung } \\
\text { pewarna buatan yang berlebihan } \\
\text { adalah? }\end{array}$ & 6 & 9 & 3 \\
\hline An. Artika & $\begin{array}{l}\text { Penyakit yang ditimbulkan jika } \\
\text { mengkonsumsi makanan yang tidak } \\
\text { ditutup dan dihinggapi lalat? }\end{array}$ & 6 & 7 & 1 \\
\hline An. Fara & $\begin{array}{l}\text { Bagaimana cara memilih makanan } \\
\text { yang sehat dan aman? }\end{array}$ & 5 & 9 & 4 \\
\hline An. Fina & $\begin{array}{l}\text { Berikut merupakan jenis jajanan } \\
\text { yang tidak sehat, Kecuali }\end{array}$ & 7 & 9 & 2 \\
\hline An. Orel & $\begin{array}{l}\text { Berikut merupakan hal - hal yang } \\
\text { harus diperhatikan sebelum } \\
\text { membeli makanan jajanan Kecuali }\end{array}$ & 5 & 9 & 4 \\
\hline
\end{tabular}

Hasil tabel diatas dapat disimpulkan bahwa terjadi peningkatan pengetahuan $41,67 \%$ dari semua peserta. Selanjutnya dari hasil penyuluhan tentang Jajanan dan Makanan Sehat pada masa pendemi, seluruh peserta sangat antusias diskusi berjalan lancar. Alhamdulilah proses penyuluhan berjalan dengan lancar dan semua peserta dan penyuluh mengikuti protkol COVID-19 . 

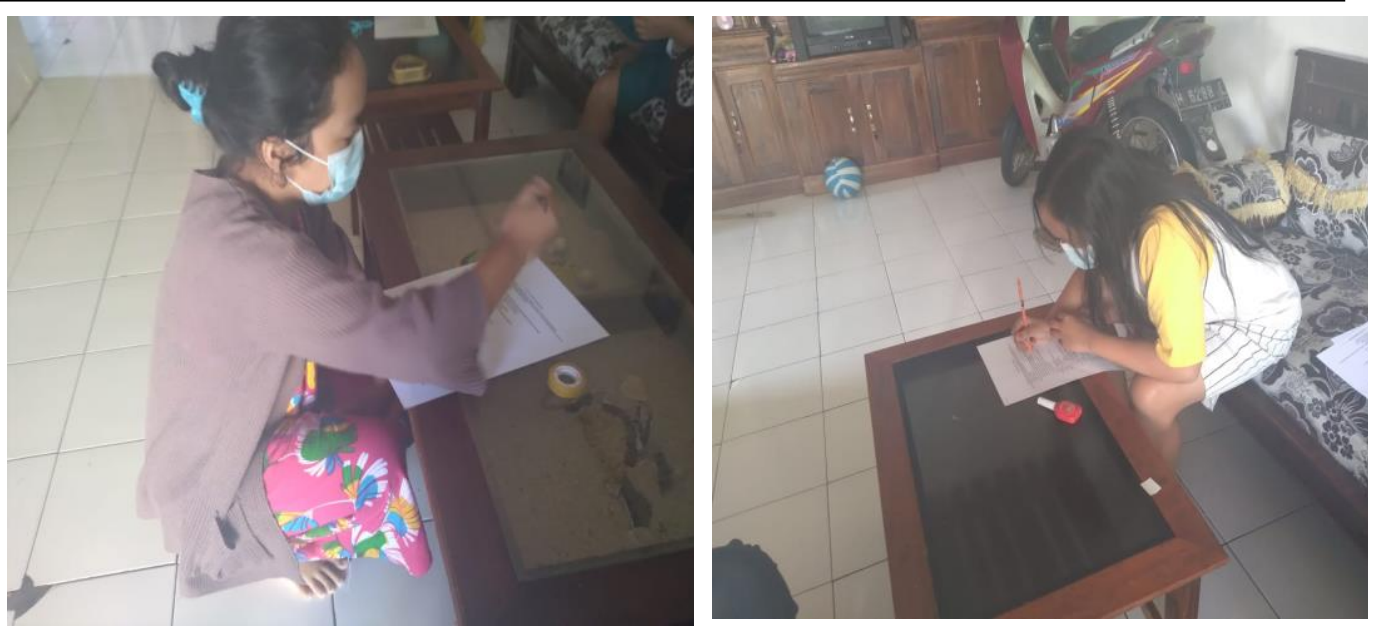

Gambar 1. Dokumentasi kegiatan penyuluhan anak SD tentang jajanan dan makanan sehat

\section{Kesimpulan}

Pelaksanaan Pengabdian Masyarakat berupa penyuluhan tentang Pelaksanaan kegiatan pengabdian kepada masyarakat dengan metode penyuluhan tentang Pendidikan Kesehatan Tentang Jajanan dan Makanan Sehat Pada Masa Pandemi COVID-19 di TPQ Warisatul Muslimin Cikal Tuntang, Kabupaten Semarang dapat dilaksanakan pada hari Rabu tanggal 30 Juni 2021, hal ini diluar prediksi karena banyaknya kasus kejadian corona di daerah tersebut. Adapun peserta yang mengikuti penyuluhan sejumlah 10 yang harusnya sampai 40 anak hal ini dikarenakan melonjaknya kasus corona didaerah tersebut, banyak anak yang harus isoman. Dan demi menjalankan prokes selama pandemi hal terbaik adalah membatasi peserta.

Peserta yang datang juga cukup banyak dan pada saat proses penyuluhan para peserta penyuluhan aktif bertanya pada saat dibuka sesi diskusi. Hasil evaluasi yang dilakukan oleh penyuluh menunjukkan bahwa penyuluhan sangat penting dan bermanfaat bagi peserta.Kemudian terjadi peningkatan pengetahuan setelah dilakukan penyuluhan.

\section{Ucapan terima kasih}

Alhamdulilah ucap syukur penulis panjatkan kehadirat Allah Azza wa Jalla dengan segala rahmat, hidayah, dan taufikNya, sehingga penulis dapat menyelesaikan Kegiatan Penyuluhan yang berjudul Pendidikan Kesehatan Tentang Jajanan dan Makanan Sehat pada Masa Pandemi COVID-19 di TPQ Warisatul Muslimin. Penulis mengucapkan terimakasih sedalam-dalamya kepada Ketua STIKES AKBIDYO, Ketua BPH Yayasan Bhakti Sosial, Wakil Ketua I, Wakil Ketua II, Wakil Ketua III, serta Ketua Prodi DIII Kebidanan yang telah mendukung terselenggaranya kegiatan pengabdian ini. Serta tidak lupa kepada seluruh ustadah di TPQ Warisatul Muslimin yang sudah membantu selama proses penyuluhan dan mengumpulkan anak - anak walau dalam masa pandemi COVID-19 dengan tetap menjaga protokol kesehatan.

\section{DAFTAR PUSTAKA}

[1] WHO, "Penyakit Bawaan Makanan :Fokus Pendidikan Kesehatan. Jakarta : EGC, 2005. 
[2] Safriana, "Perilaku Memilih Jajanan Pada Siswa Sekolah Dasar di SDN Garot Kecamatan Darul Imarah Kabupaten Aceh Besar Tahun 2012," Universitas Indonesia, 2012.

[3] Departemen Kesehatan RI, Undang-Undang Republik Indonesia Nomor 36 Tahun 2009 Tentang Kesehatan. 2010.

[4] Kementerian Kesehatan RI, Profil Kesehatan Indonesia 2017. Jakarta: Kementerian Kesehatan RI, 2019.

[5] Judarwanto W, "Perilaku makan anak sekolah. Direktorat Bina Gizi Kementerian Kesehatan Republik Indonesia," 2011.

[6] U. Fahmi, Manajemen Penyakit Berbasis Wilayah. Jakarta: Kompas, 2013. 